\title{
The Conceptual Learning of Physics in Slovenian Secondary Schools
}

\author{
Simon Ülen ${ }^{1,2}$, Ivan Gerlič ${ }^{1}$ \\ ${ }^{1}$ Franca Miklošiča Grammar School, Prešernova cesta 34, 9240 Ljutomer, Slovenia \\ ${ }^{2}$ University of Maribor, Faculty of Natural Sciences and Mathematics, Koroška cesta 160, 2000 Maribor, Slovenia, \\ simon.uelen@guest.arnes.si, ivan.gerlic@uni-mb.si
}

\begin{abstract}
In the last decade, educational researchers have been intensively searching for new, innovative teaching approaches. Information and Communication Technology (ICT) has a great didactic potential and project COLOS (Conceptual Learning of Science) encourages the use of ICT in the contemporary educational process. In this paper we present the conceptual learning of Physics. With experimental research we investigated the effectiveness of such learning in Slovenian secondary school. Two groups of third-year students who were enrolled in an introductory Physics course participated in the study. In the experimental group students were taught through the conceptual learning and in the control group a traditional expository instruction was used. We examined the knowledge of students after carrying out lessons specifically on the topic of Electricity. Five thinking processes were assessed - Knowledge (Recall), Analysis, Comparison, Inference and Evaluation. We found that the conceptual learning was more effective than the traditional instruction.
\end{abstract}

Key words: traditional instruction, conceptual learning of Physics, Information and Communication Technology (ICT), simulations, physlets.

\section{Introduction}

In the last two decades many researchers have been searching for new, innovative approaches in teaching Physics. Some of them have systematically collected and put in order previous researches by specific domains. The articles by McDermott and Redish (1999) and Thacker (2003) include more than 500 researches and projects about the innovative teaching approaches. Many of previous studies include the investigation on the potential of computer simulations in the contemporary Physics teaching (Podolefsky, Perkins and Adams, 2010; Sadaghiani, 2011; Lee, Guo \& Ho, 2008; Wieman, 2007).

For example, Wieman (2007) noted that computer simulations are new, very powerful ways to engage students in educational activities. To exploit the great potential of Information and Communication Technology was one of the key goals of the COLOS (Conceptual Learning of Science) project (Härtel, 1995). With the rapid progress of the computer technology in recent years, the conceptual learning is fast becoming a very promising teaching approach, also in the field of Physics.

\section{The conceptual learning of Physics}

Motivation is one of the key problems in Natural and Technical Sciences Education. In Education, particularly by the teaching and learning of Physics, the motivation and active knowledge of the students is of paramount importance. Passive, unmotivated students, a template of pattern solving principles and minimal creativity learning have no future in contemporary education. Computers and ICT have a didactic potential because of their ability to incorporate motivation and research problem solving approach into Education. Active involvement and problem solving are important characteristics of the conceptual learning of science, which has been promoted by members of the COLOS group. Project COLOS was founded in 1988 by Zvonko Fazarinc, a professor at Stanford University (Muller et al., 1995). The main goals of the project were to improve teaching and learning, also with the help of ICT, and to stimulate the production and use of software for education.

\subsection{The role of Physlets in the conceptual learning}

The conceptual learning of Physics often uses models, animations and simulations for problem solving approaches (Christian et al., 2006). In the beginning simulations required an expensive graphics workstation (e.g. SUN, HP, Silicon Graphics ...) but the advances in personal computer hardware and especially platform independent software, such as Flash

Received: $13^{\text {th }}$ December 2011; revised $4^{\text {th }}$ February 2012; accepted $28^{\text {th }}$ March 2012 
and Java, have provided tremendous new capabilities. The World Wide Web makes it possible that, if a simulation is written in a language such as Flash or Java, it can be run through a standard browser anywhere in the world. This capability brings many opportunities to improve educational processes. In the last decade we started using java programs - applets; when an applet is orientated on a small, specific domain of physics, we talk about physlets (Christian et al., 2006).

The question how to effectively support the conceptual learning has captured many researchers` attention (Cheng, 1999). Physlets could effectively support such learning because of their special characteristics. In the first place, Physlets are interactive materials, where processes happen at certain intervals and there is an interaction between the model and the student. Students have the possibility of changing the conditions and immediately observing the impact. In addition, Physlets enable us, when dealing with new physical phenomena, to change relevant parameters and immediately see the consequences of our actions. Consequently, that could help students to understand the main concepts of the phenomenon.

In the didactical sense there are three different types of Physlets:

- Illustrations: we use them for the presentation of the phenomena,

- Explorations: physlets for the exploration of specific physical phenomena,

- Problems: they are useful for examining the knowledge that students have acquired.

Figure 1 shows a Physlet for the exploration of the simple harmonic motion.

Physlets can be used as simulation models in numerous learning web applications. They can be used as an element of almost any curriculum with almost any teaching approach, so they could also play an important role in the conceptual learning of Physics.

\section{2 The practical application of conceptual learning}

The basic and primary goal of conceptual learning of Physics for the students is to experience the phenomena before receiving its theoretical and mathematical background (Gerlič, 2006). Students should become familiar with the concepts of phenomenon or law and equations can be introduced later if needed, presenting them as they really are - a model trying to present reality (Muller et al., 1995).

Following the main goals of the conceptual learning of Physics, in this study the teacher had quite a different role through the conceptual learning than through the traditional lessons. He was not that of the authoritative fount of all knowledge, but that of the initiator, organizer, adviser and connector of the whole process. The big emphasis was on the understanding of the basic concepts of the particular phenomenon. Communication was vertical and horizontal, so teacher immediately got feedback from students about their understanding of the task or phenomenon. There was a bit more noise in the classroom because the students worked in pairs. Each lesson contained following main stages:

- The starting-point of the lesson was checking the preknowledge of the students, usually through the discussion with the students.

- Motivating students through exposing them to a physical example of the particular topic, usually involving a demonstrational experiment.

- Researching the phenomenon with the help of the conceptual based interactive materials (learning of the topic).

- Checking of the deepness of knowledge and understanding of phenomena, nature law, conceptions etc. in new problem based situations, also with the conceptual based interactive materials.

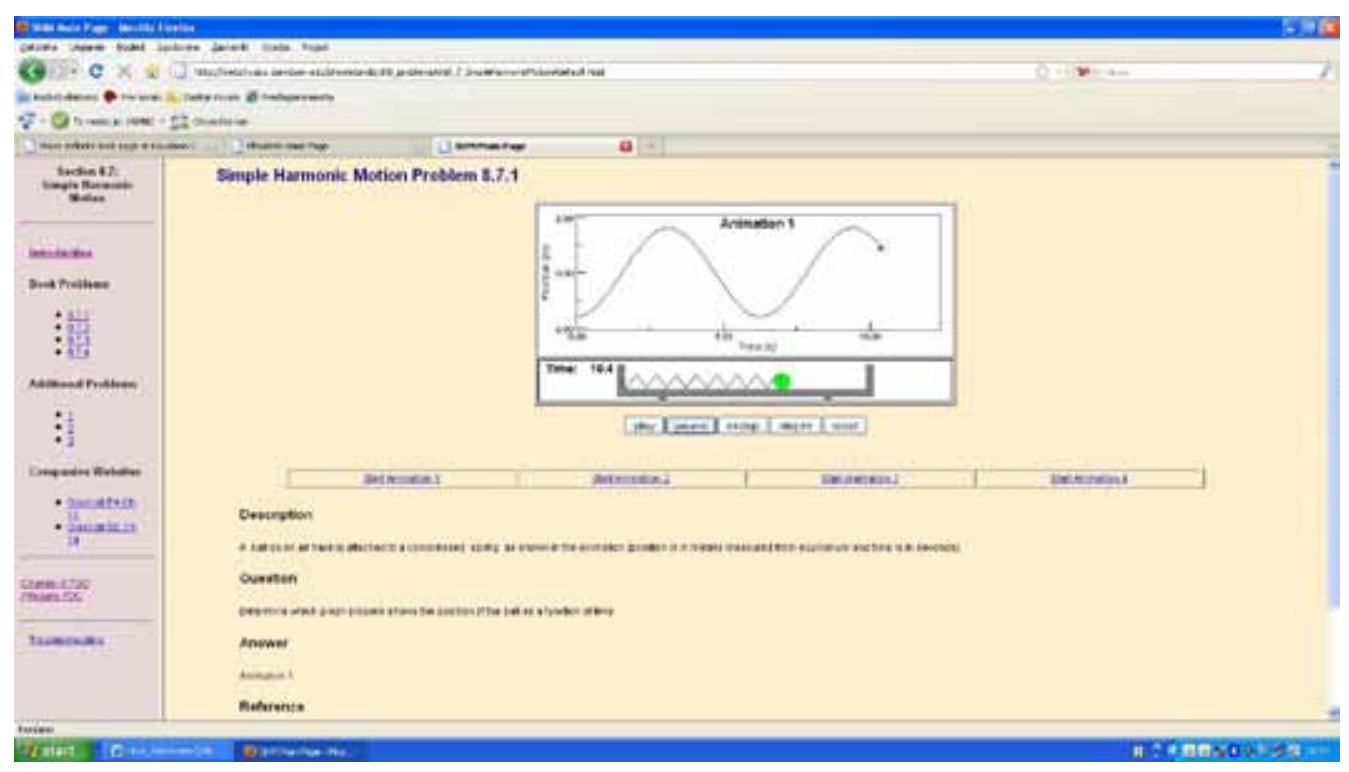

Figure 1: Simple Harmonic Motion Problem (Christian et al., 2006). 


\section{Purpose of the study}

The main goal of the study was to investigate the effects of the conceptual learning of Physics in comparison to the traditional expository instruction when teaching the topics in the field of Electricity, in the third class of Slovenian 4-Year High School.

\section{Methodology}

We carried out the One Factory Experiment with classes as comparison groups. The same teacher was teaching two groups of students, covering the following topics: Electric field, Coulombs` law, Force on the charge in the plane and Electric fluid. Each lesson was carried out with the two different teaching approaches: one group was taught through the conceptual learning and the other group was taught through the traditional expository instruction. All lessons were prepared with consideration of the curriculum for Slovenian Secondary Schools (Ministry of Education and Sport, 2008). The traditional instruction was supported with standard didactical material - textbooks; for the conceptual learning we prepared interactive worksheets with appropriate Physlets.

\section{Research sample}

The research sample consisted of the third grade students, of which one group presented the experimental group $(\mathrm{N}=33)$, and the other group $(\mathrm{N}=33)$ functioning as the control group.

\section{Data collection procedure}

The research took place in Secondary School "Gimnazija Franca Miklošiča Ljutomer" and was carried out in October and November in the academic year 2011/2012. We were especially interested in the effectiveness of the conceptual learning in the field of five thinking processes- Knowledge, Analyse, Compare, Infer and Evaluate (Phye, 1997):

- Knowledge is the lower thinking process and involves just interpretation of memorized data.

- Analysis involves dividing a whole into its distinctive elements and understanding the relationship of the parts to the whole.

- Comparison involves identifying similarities and differences and understanding their overall significance.

- Inference and interpretation involve use of various forms of inductive and deductive reasoning.

- Evaluation involves making judgments about what to believe on explicit criteria and supporting evidence.

We tested students' knowledge before the experiment (pre-test) and after the experiment (post-test). To see the structure of the test, the sample question is provided in Figure 2 bellow.

\section{Results}

The results of descriptive statistics are presented in Figure 3; there are the pre-test and post-test results.

As seen in Figure 3 (a), there were no major differences in the pre-test results between the experimental and the control group across every taxonomic level of knowledge. It could be concluded that students from the experimental and the control group were comparable enough in their pre-knowledge, before starting the lectures.

However, after carrying out lessons, there were major differences between the results of students, who were taught in the conceptual way (experimental group) and the results

The speed of proton 1 in the magnetic field is two times slower than the speed of proton 2 and at the same time the magnetic field that proton 1 is entering, is two times larger than the magnetic field, when proton 2 is entering (see picture on the left). Which of the following statements best describes the movement of these two charged particles in the magnetic fields?

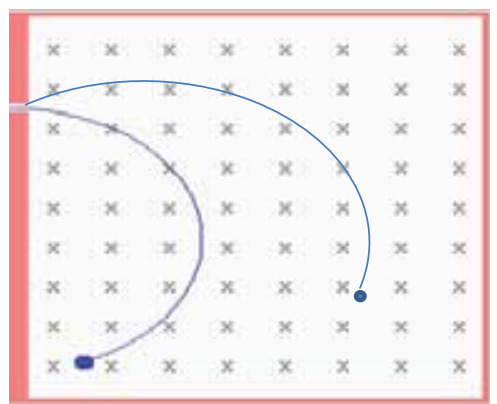

A. The radius of the circulation of proton 1 is smaller than the radius of proton 2 .

B. The radius of the circulation of proton 1 is larger than the radius of proton 2.

C. The radius of the circulation of proton 1 is equal to the radius of proton 2 .

D. The radius of the circulation of proton 1 is two times larger than the radius of proton 2 . 


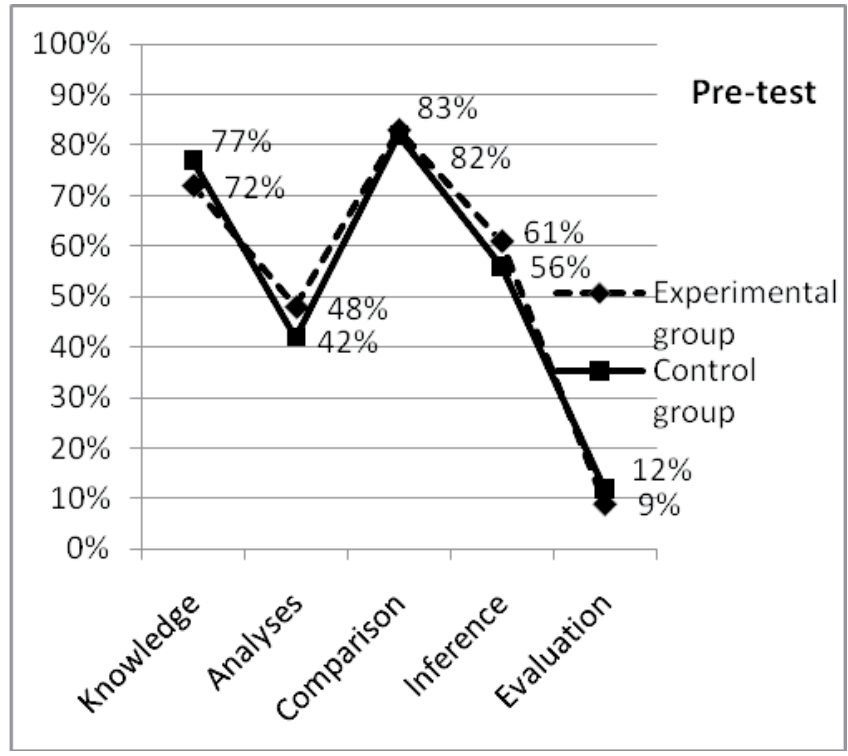

(a)

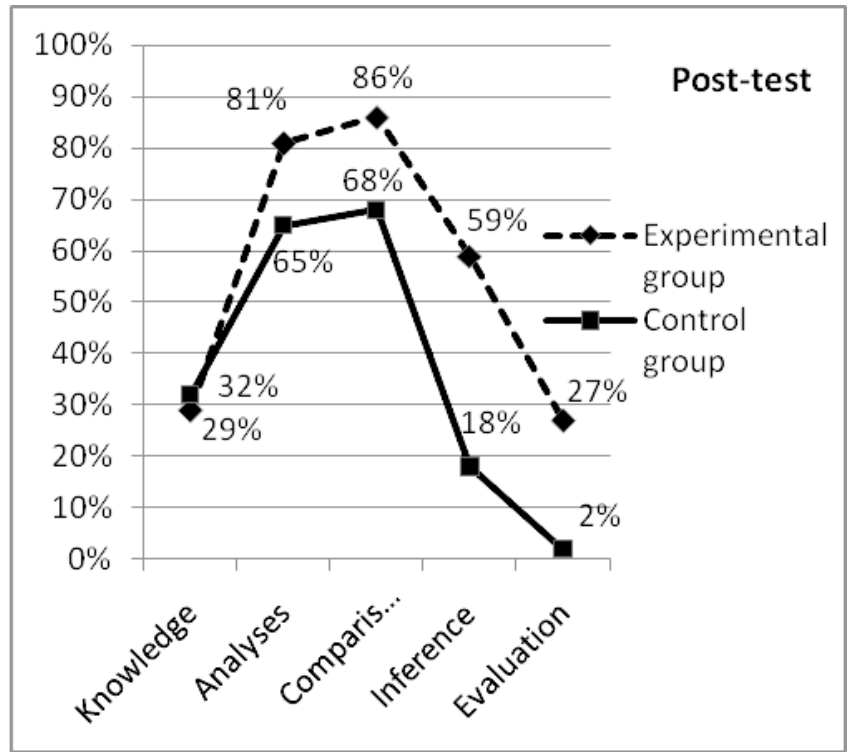

(b)

Figure 3: (a) Pre-test results on the single thinking process; (b) Post-test results on the single thinking process.

of students, who were taught traditionally (control group). As seen in Figure 3 (b), students in the experimental group achieved better results than those in the control group on each higher thinking process (Analysis, Comparison, Inference and Evaluation). At the Analysis and the Comparison the differences were $16 \%$ and $18 \%$ and at the Inference and the Evaluation there were the biggest advantages of students from the experimental group ( $41 \%$ and $25 \%$ ).

\section{Conclusions}

The principal role of the conceptual learning of Physics is the empirical experience of a naturalistic law, rather than its mathematical background. In this study we have investigated the effectiveness of such a learning approach in Slovenian Secondary School. We compared the post-test results of students who were taught through the conceptual learning, with the emphasis on the usage of computers and autonomous researching (experimental group), with the results of students who were taught through the expository instruction (control group). The results of this study indicate that the conceptual learning enables students a better understanding of physical concepts and consequently, enhanced students` learning outcomes.

The new generation of students and the rapid development of modern technology are encouraging the educational researchers to keep searching for new, appropriate teaching approaches. This study confirms that ICT can effectively support the use of innovative methods of teaching and can help to improve the existing teaching approaches. On the other hand, using ICT does not mean that teachers should forget and neglect the experiment as the basic instrument in Physics teaching; however, they should take the advantages of the modern technology in the educational process wherever this is possible and reasonable.

In conclusion, the results of this study indicate that the conceptual learning of Physics could be, in the selected didactical cases, the alternative or the completion to the existing approaches in Physics teaching. In light of the results of this study, teachers who use just traditional methods in their programmes because of time constraints but want to improve the effectiveness of their instruction may review the potential benefits of Physlets and the conceptual learning of Physics.

\section{References}

Cheng, P. C-H. (1999). Unlocking conceptual learning in mathematics and science with effective representational systems. Computer \& Education, 33: 109-130, DOI: 10.1016\%2FS03601315\%2899\%2900028-7

Christian, W., Belloni, M. \& Divjak, S. (2006). Fizika s fizleti. Interaktivne predstavitve in raziskave za uvod $v$ fiziko. [Physlet Physics. Interactive Illustrations and Explorations for Introductory Physics]. Zavod Republike Slovenije za šolstvo, Ljubljana.

Gerlič, I. (2006). Konceptualno učenje in interaktivna gradiva. [Conceptual learning and Interactive Materials]. Organizacija, 39(8): 472-474.

Härtel, H. (1995). (CoLoS): Conceptual Learning of Science. IPNInstitute for Science Education at the University Kiel.

Lee, Y.-F., Guo, Y., \& Ho, H.-J. (2008). Explore effective Use of Computer Simulations for Physics education. Journal of Computers in Mathematics and Science Teaching, 27(4), 453 - 455. Available March 21, 2012, from http://editlib.org/noaccess $/ 25239$ 
McDermott, C. L. (1991). What we teach and what is learned-Closing the gap. American Journal of Physics, 59 (4), 301-315, DOI: $10.1119 \% 2 \mathrm{~F} 1.16539$

McDermott, C. L. \& Redish, E. F. (1999). Resource letter: PER-1: Physics Education Research. American Journal of Physics, 67 (9): 755 - 767, DOI: $10.1119 \% 2 F 1.19122$

Ministry of Education and Sport. (2008). Curriculum of Physics for Grammar School. Retrieved September 5, 2008, from http:// portal.mss.edus.si/msswww/programi2010/programi/media/ pdf/un_gimnazija/un_fizika_gimn.pdf

Muller, D., Mariaux, L. \& Nicolas, A. (1995). The Colos Project - Applications in the domain of Electrical Engineering. Proc. of IEEE-APS Symp, Newport-Beach (CA), June 18 - 23, 476 -479 .

Phye, G. D. (1997). Handbook of Classroom Assessment: Learning, Adjustment and Achievement. Academic Press, ZDA.

Podolefsky, N. S., Perkins, K. K., \& Adams, W. K. (2010). Factors promoting engaged exploration with computer simulations, Phys. Rev. ST Phys. Educ. Res. 6(2), DOI: 10.1103\%2FPhysRevSTPER.6.020117

Sadaghiani, H. R. (2011). Using multimedia learning modules in a hybrid-online course in electricity and magnetism. Phys. Rev. ST Phys. Educ. Res. 7, DOI: 10.1103\%2FPhysRevSTPER.7.010102

Thacker B. A. (2003). Recent advances in classroom physics. Rep. Prog. Phys. 66(19): 1833-1864, DOI: 10.1088\%2F00344885\%2F66\%2F10\%2FR07

Wieman, C. E. Perkins, K. K. \& Adams W. K. (2008). Oersted Medal Lecture 2007: Interactive simulations for teaching physics: What works, what doesn't, any why. American Journal of Physics, 76 (4): 393, DOI: 10.1119/1.2815365
Simon Ülen currently holds the position of teacher of Physics at a 4-Year-Grammar School in Ljutomer. As Assistant of Physics he also cooperates with the Faculty of Natural Sciences and Mathematics, University of Maribor. He has 10 years of work experience. He gained his research experience at postgraduate level exploring modern teaching and learning approaches, with emphasis on the conceptual learning of physics. As a member of the Development Team for Physics he participated in the National Educational Project for the Renovation of Slovenian Grammar Schools.

Ivan Gerlič is Associate Professor of Didactics of Physics and Didactics of Informatics at the University of Maribor, Faculty of Natural Sciences and Mathematics. He is Chair of Centre for Didactics of Physics and Laboratory for Computation Physics, researcher and author of numerous scientific articles, monographs, higher, secondary and primary schools textbooks, manuals in the field of physics, computing, informatics and multimedia. His research and development interests are: Didactic of Physics, Didactics of Computers use in education - ICT, Educational Technology, ICT Video Production (Educational scenarios, Video Production, Coding), Multimedia (Didactic and Design), Video on Demand, Distance Education and Tele Learning, Educational Internet Application Design, New Video Technologies, ICT for Handicapped Persons, Electronic Designing. 